oral contraceptives makes this unlikely. An alternative explanation is that the hormonal changes induced by pregnancy and oral contraceptives cause an increase in membrane permeability to sodium and stimulate sodium efflux. If this were the case then there must be an agent present in normal pregnancy which stabilises the cell membrane and which is absent or diminished in hypertensive pregnancy.

It has been suggested that prostacyclin mediates the tolerance to angiotensin II in normal pregnancy and that its relative lack is responsible for the onset of hypertension. ${ }^{7}$ This hypothesis is compatible with our results, since it has also been found that oral contraceptives inhibit prostacyclin production, ${ }^{8}$ and that long term use of oral contraceptives is associated with a significant and reversible rise in blood pressure. ${ }^{9}$ Our results offer an explanation for this phenomenon, since the increased cell membrane permeability to sodium occurring in women taking oral contraceptives was similar to that occurring in hypertensive pregnancy. Indeed it has been suggested that women most likely to have a rise in blood pressure while taking the pill are those who have had pre-eclampsia." "11

In order properly to evaluate the hormonal influences of pregnancy and oral contraceptives on cellular sodium handling longitudinal studies are required so that changes within subjects can be monitored.

This study was partly supported by a grant from the Central Birmingham Health District Endowment Research Committee.

\section{References}

1 Gant NF, Daley GL, Chand S, Macdonald PC. A study of angiotensin II pressor response throughout primigravid pregnancy. 7 Clin Invest 1973;52:2682-9.

${ }^{2}$ Edmondson RPS, Hilton PJ, Thomas RD, Patrick J, Jones NF. Abnormal leucocyte composition and sodium transport in essential hypertension. Lancet $1975 ; \mathrm{i}: 1003-5$.

${ }^{3}$ Forrester TE, Alleyne AO. Leucocyte electrolytes and sodium efflux rate constants in hypertension of pre-eclampsia. Clin Sci 1980;59:199s-201s.

- Weissberg PL, West MJ, Woods KL. An improved method for measuring intracellular electrolytes in erythrocytes and the effects of cold storage. Clin Chim Acta 1983;129:85-9.

${ }^{5}$ Hytten FE, Thomson AM, Taggart M. Total body water in normal pregnancy. Fournal of Obstetrics and Gynaecology of the British Commonwealth 1966;73:553-61.

${ }^{6}$ Rubython J, Morgan DB. The effect of pregnancy and pregnancy induced hypertension on active sodium transport in the erythrocyte. Clin Sci $1983 ; 64: 57 \mathrm{P}$

7 Broughton Pipkin F, Hunter JC, Turner SR, O'Brien PMS. Prostaglandin $\mathrm{E}_{2}$ attenuates the pressor response to angiotensin II in pregnant subjects but not in non-pregnant subjects. Am $\mathcal{F}$ Obstet Gynecol 1982;142:168-76.

* Ylikorkala O, Puolakkaj, Vhnikka L. The effect of oral contraceptives on anti-aggregatory prostacyclin and pro-aggregatory thromboxane $\mathrm{A}_{2}$ in humans. Am f Obstet Gynecol 1982;142:573-6.

${ }^{9}$ Weir RJ, Briggs E, Mack A, Naismith L, Taylor L, Wilson E. Blood pressure in women taking oral contraceptives. Br Med F 1974;i:533-5.

10 Spellacy WN, Birk SA. The effects of intrauterine devices, oral contraceptives, estrogens, and progestogens on blood pressure. Am $\mathcal{f}$ Obstet Gynecol 1972;112:912-9.

1 Clezy TM, Foy BN, Hodge RL, Lumbers ER. Oral contraceptives and hypertension. Br Heart $\mathcal{F} 1972 ; 34: 1238-43$.

(Accepted 1 fune 198.3)

\title{
Intermittent cyclophosphamide in refractory rheumatoid arthritis
}

\author{
KIM HØRSLEV-PETERSEN, JANNIE M BEYER, PEKKA HELIN
}

\begin{abstract}
Three patients with refractory rheumatoid arthritis were treated with oral cyclophosphamide; in two cases this was supplemented with pulse treatment with methylprednisolone. Long term remission was induced in all three patients and was sustained until follow up at least nine months after the methylprednisolone was stopped. Leucopenia occurred but resolved when cyclophosphamide was reduced from daily to intermittent dosing.

Intermittent treatment with cyclophosphamide, possibly in conjunction with pulses of methylprednisolone, may induce remission in patients with rheumatoid arthritis refractory to other forms of treatment.
\end{abstract}

\section{Introduction}

Recently the possibility of managing refractory rheumatoid arthritis has increased with the availability of various immuno-

\footnotetext{
Department of Rheumatology, Kong Christian den X's Gigthospital, DK-6300 Graasten, Denmark

KIM HØRSLEV-PE TERSEN, MD, registrar

JANNIE $M$ BEYER, MD, senior house officer

PEKKA HELIN, MD, PHD, head of department

Correspondence to: Dr K Horslev-Petersen.
}

suppressive regimens, among them cytostatic treatment and intravenous methylprednisolone pulse treatment. Use of a combination of corticosteroids and intermittent cytostatic treatment, which is well established in treating cancer, ${ }^{1}$ has not been described in rheumatoid arthritis resistant to treatment, although Fosdick et al reported using intermittent cyclophosphamide treatment in a few patients with rheumatoid arthritis. ${ }^{2}$

We report the effect of combined intermittent cyclophosphamide treatment and methylprednisolone in three patients with disabling rheumatoid arthritis that had been impossible to control adequately either because of toxic side effects or because of failure to respond to treatment.

\footnotetext{
Case reports

Case 1-A 60 year old woman with seropositive erosive rheumatoid arthritis of four years' duration had been treated with low dose prednisone, gold, and penicillamine. In July 1981, as disease activity persisted (table), oral cyclophosphamide was started at a dose of $100 \mathrm{mg} /$ day, which was reduced to $50 \mathrm{mg}$ /day when leucopenia $\left(2.9 \times 10^{y} / 1\right)$ occurred. As the leucopenia continued intermittent treatment with cyclophosphamide $100 \mathrm{mg}$ every three and subsequently every four days was begun, which completely abolished the symptoms. In May 1983 the disease was still in remission (table).

Case 2-A 51 year old woman with seropositive erosive rheumatoid arthritis of six years' duration had received treatment with gold, chloroquine, penicillamine, and azathioprine. As her disease remained active (table), in September 1981 she was placed on a regimen of methylprednisolone pulse treatment $1 \mathrm{~g}$ intravenously on four successive days and oral cyclophosphamide $100 \mathrm{mg} /$ day. As the disease activity did not abate, repeated courses of methylprednisolone pulse
} 


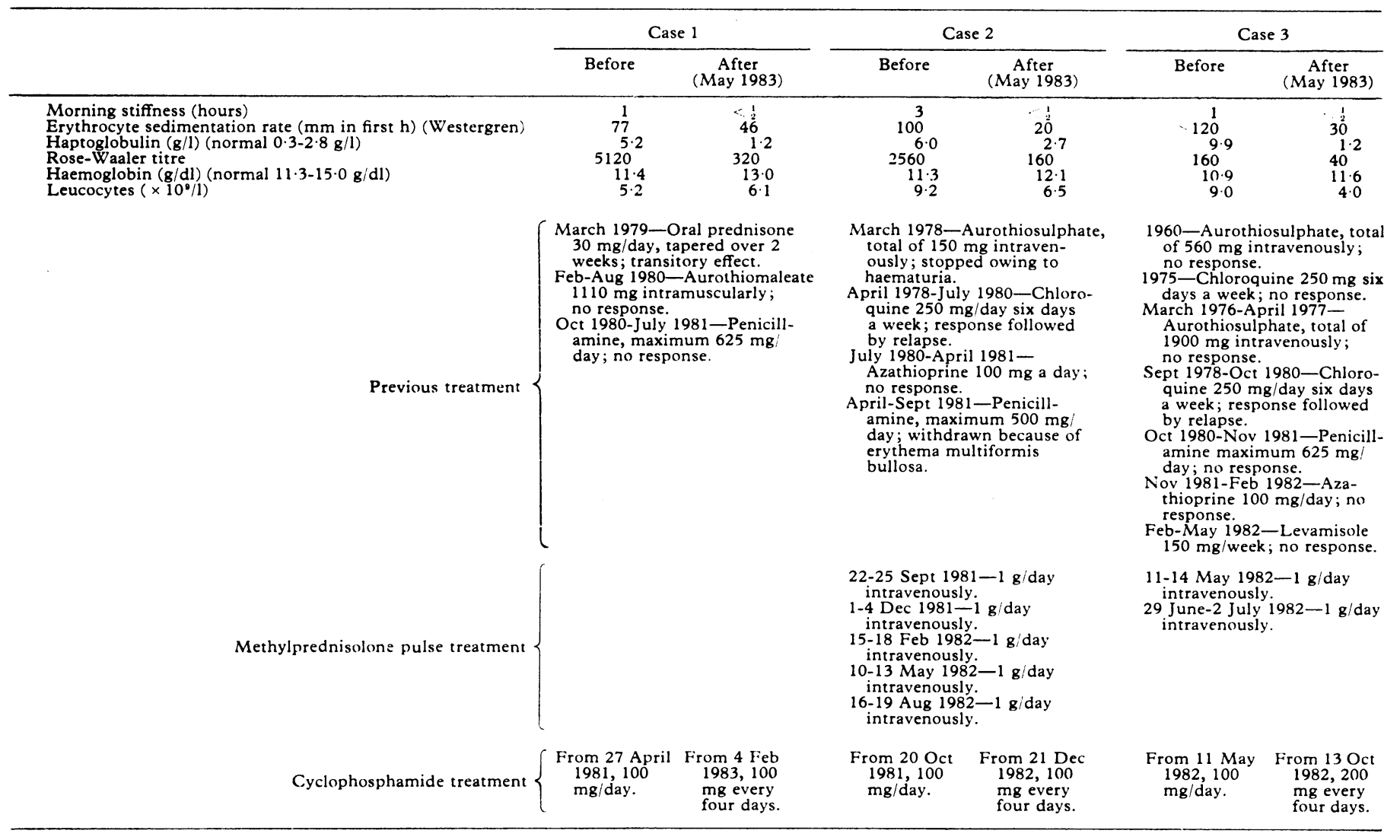

treatment were given until August 1982, when leucopenia $\left(2.7 \times 10^{9} / 1\right)$ occurred. Treatment was changed to intermittent cyclophosphamide $100 \mathrm{mg}$ every three and later every four days, which abolished the symptoms. In May 1983 the disease was still in remission (table).

Case 3-A 51 year old woman with a 25 year history of seropositive erosive rheumatoid arthritis had been treated with gold, chloroquine, low dose prednisone, penicillamine, azathioprine, and levamisole. In May 1982 because of persisting disease activity (table) she was given methylprednisolone pulse treatment $1 \mathrm{~g}$ intravenously on four successive days and oral cyclophosphamide $100 \mathrm{mg}$ daily increasing to 150 and $100 \mathrm{mg}$ on alternate days. Methylprednisolone pulse treatment was repeated in June 1982. Leucopenia $\left(3.0 \times 10^{9} / 1\right)$ occurred, and in September 1982 intermittent cyclphosphamide treatment was begun with $100 \mathrm{mg}$ every two and later every four days; this completely suppressed the disease. In May 1983 the disease was still in remission (table).

\section{Discussion}

Immunosuppressive agents are increasingly used to manage rheumatoid arthritis, the purpose being to suppress the abnormal immune mechanisms that are supposed to play an essential part in the pathogenesis of the disease. Disease activity may be controlled by cyclophosphamide, ${ }^{23}$ but continuous treatment is often complicated by leucopenia; the degree of leucopenia is directly proportional to the dosage of cyclophosphamide. ${ }^{4}$ Fosdick et al used intermittent cyclophosphamide treatment in patients with rheumatoid arthritis in whom the leucocyte count tended to drop. ${ }^{2}$

Between June 1981 and June 1983 we gave intermittent cyclophosphamide treatment to three patients with refractory seropositive erosive rheumatoid arthritis; in two this treatment was supplemented initially by courses of methylprednisolone pulse treatment, but in both cases methylprednisolone was stopped at least nine months before the follow up examination in May 1983. This regimen induced long term remission in all three patients. Toxic reactions were avoided and leucopoenia curbed, and intercurrent infections requiring treatment did not occur.

Hazleman found an increased incidence of infection during immunosuppressive treatment, particularly when it was combined with massive doses of corticosteroids. ${ }^{5}$ Our patients had no infections. The explanation might be that the intermittent cytostatic treatment given was less immunosuppressive, or that glucocorticosteroids given as methylprednisolone pulse treatment are less immunosuppressive than continuous oral glucocorticosteroids. Bladder fibrosis is another side effect that seems to be related to the dosage of cyclophosphamide. None of our patients had symptoms of the urinary tract.

In conclusion, we consider that intermittent cyclophosphamide treatment, possibly combined with courses of methylprednisolone pulse treatment, may produce long term remission in patients with resistant forms of rheumatoid arthritis, having a lower tendency to induce leucopenia and, possibly, a reduced risk of late adverse reactions.

\section{References}

1 Devita VT Jr, Serpick AA, Carbone PP. Combination chemotherapy in the treatment of advanced Hodgkin's disease. Ann Intern Med 1970;73: 881-95.

${ }^{2}$ Fosdick WM, Parsons JL, Hill DF. Long-term cyclophosphamide therapy in rheumatoid arthritis. Arthritis Rheum 1968;11:151-61.

${ }^{3}$ Cooperating Clinics Committee of the American Rheumatism Association. A controlled trial of cyclophosphamide in rheumatoid arthritis. $N$ Engl $\mathfrak{f}$ Med 1970;283:883-9.

' Williams HJ, Reading JC, Ward JR, O'Brien WM. Comparison of high and low dose cyclophosphamide therapy in rheumatoid arthritis. Arthritis Rheum 1980;23:521-7.

${ }^{5}$ Hazleman BL. A comparative incidence of malignant disease in rheumatoid arthritics exposed to different treatment regimens. Ann Rheum Dis $1982 ; 41$, suppl $1: 12-7$.

(Accepted 17 fune 1983) 